\title{
The Sexual Function of Primiparous Women after Normal Delivery and Cesarean Section According to the Female Sexual Function Index
}

\author{
Eighty Mardiyan Kurniawati ${ }^{1 *}$, Sandy Irwanto ${ }^{1}$, Nalini Muhdi ${ }^{2}$ \\ ${ }^{1}$ Department of Obstetrics and Gynecology, Urogynecology Reconstructive Division, Faculty of Medicine, Universitas \\ Airlangga, Dr. Soetomo Hospital, Surabaya, Indonesia; ${ }^{2}$ Department of Psychiatry, Faculty of Medicine, Universitas Airlangga, \\ Dr. Soetomo Hospital, Surabaya, Indonesia
}

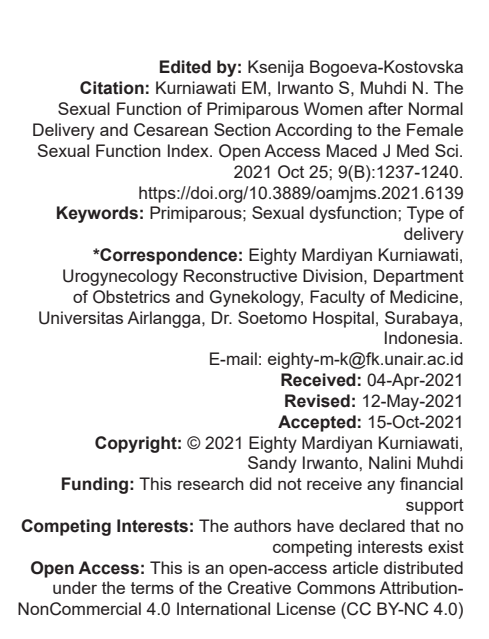

\begin{abstract}
BACKGROUND: Various anatomical and physiological changes occur to provide a suitable environment for fetal development during pregnancy. Changes in body shape and other physical changes also undergo changes and are associated with postpartum sexual dysfunction.

AIM: This study aims to measure and determine the difference in female sexual function index scores for primiparous women post normal delivery and post-cesarean section.

METHODS: An observational analytic study with a cross-sectional study design conducted in a hospital. This study involved 60 women with inclusion criteria aged 20-35 years, primiparous women with post-term pregnancy, primiparous women after normal delivery and cesarean section at 3-4 months, women who were married and living with their husbands and were willing to participate in this study. Data were analyzed descriptively and statistically.

RESULTS: The results showed that the cause of perineal damage was mostly due to the mediolateral episiotomy, the degree of perineal damage with Grade II status, and there was variation in the indication of an elective cesarean section. The statistical test results show that there was no difference in the type of delivery, both normal delivery and cesarean delivery on desire, arousal, satisfaction, lubrication, orgasm, and dyspareunia and the total female sexual index in primiparous $(P>0.05)$

CONCLUSION: This study recommends that in primiparous women care, it is not advisable to choose one type of delivery as a form of prevention of postpartum sexual dysfunction. In addition, in the management of complaints of sexual dysfunction in primiparous it is not required to consider the type of delivery as the main cause.
\end{abstract}

\section{Introduction}

Pregnancy and childbirth are natural processes that women experience. This natural process has an impact on both physiological changes and pathological changes. During pregnancy, the physiological processes that the female body experiences include various anatomical and physiological changes to provide a suitable environment for fetal development, to meet increased metabolic needs, and to prepare for labor [1], [2]. Pregnancy causes a variety of hormonal, immunological, and metabolic changes that have a significant effect on a woman's body. Changes in circulating hormone levels increased intravascular volume, and compression of the enlarged uterus underlie complex physiological adaptations that are important for fetal development [3].

These physiological changes are also related to changes in the shape of a woman's body as well as several other postpartum complaints. Women have unrealistic expectations of their postpartum body, thus affecting the state of postpartum sexual intercourse [4]. One of the organs that are affected is the female genitals. Body image satisfaction influences weight regulation and can contribute to a long-term healthy lifestyle after pregnancy [5]. The prevalence of overweight and obesity is associated with gestational weight gain which affects changes in maternal body composition during pregnancy [6]. Trauma to the perineum, levator ani complex, and anal sphincter frequently occurs during vaginal delivery but is often underdiagnosed clinically, and many women are unaware of the potential for longterm damage. These changes interfere with women in continuing postpartum sexual intercourse. Many postpartum women suffer from problems such as dyspareunia, loss of desire, loss of vaginal lubrication, pain during orgasm, postpartum bleeding, itching, and burning. 1-3 An estimated $20 \%$ of women have dyspareunia in their first three pregnancies. MONTHs postpartum with persistent pain in one in five women up to 6 months after delivery and one in nine unable to continue sexual relations [7]. 
Postpartum sexual change is an aspect that affects the quality of life of women. Research shows that postpartum sexual dysfunction is the most common sexual dysfunction found. The high prevalence of sexual disorders requires that the health care system pay attention to this aspect. A more intensive concern needs to focus on women's sexual health including early diagnosis and treatment of partner sexual dysfunction, especially during pregnancy and after delivery [8].

In one study, parity had an effect on women's sexual function; Primiparous women have dyspareunia more than multiparous women. This can be explained by the higher rates of severe perineal trauma and instrumental delivery in the primiparous. In addition, primiparous usually feel less secure about postpartum sexual life due to inexperience. In addition, women who are not sexually active at 12 weeks of gestation and women who are older at delivery have higher levels of dissatisfaction with sexual intercourse 1 year after delivery [9].

Research on sexual dysfunction in primiparous women after childbirth needs to be done, especially regarding whether cesarean delivery or normal/vaginal delivery affects the female sexual function index (FSFI). This study focused on whether the sexual function scores of desire, arousal, orgasm, dyspareunia, lubrication, and satisfaction of primiparous women post normal delivery were lower than after cesarean section. The results of the study are expected to provide preliminary information regarding the effect of the mode of delivery on sexual function, prevention of labor trauma and can be used as a reference for future researchers in the field of urogynecology.

This study aims to measure and determine the difference in the FSFI score of the sexual function of primiparous women after normal delivery and post-cesarean section.

\section{Methods}

This research was conducted by measuring the FSFI, namely the function of sex desire, arousal, orgasm, dyspareunia, lubrication, and satisfaction of primiparous women after normal delivery and after cesarean section. After that, it will be known the difference in the scores of the FSFI of primiparous women after normal delivery and post-cesarean section. This research is an observational analytic with cross-sectional study design. The research was conducted at the teaching hospital Dr. Soetomo, Indonesia and Network Hospital. This study involved women with inclusion criteria aged 20-35 years, primiparous women with postterm pregnancy, primiparous women after normal delivery and cesarean section at 3-4 months, women who were married and living with their husbands and were willing to participate in this study. This study had exclusion criteria, namely, women who were suffering from infections of the pelvic cavity, endometriosis, vulvodynia, had had pelvic surgery, emergency cesarean section, vaginal delivery with instruments, perineal rupture levels 3 and 4, taking drugs with side effects on sexual function, suffering from postpartum depression or having problems with marital conflict, suffering from medical diseases such as hypertension, diabetes mellitus, and serious complications of childbirth and sexual dysfunction before pregnancy. The sample size was 30 for each group of cesarean deliveries and normal deliveries. If the data were analyzed normally, the independent t-test was used to compare the mean FSFI measurement between women after normal delivery and post-cesarean section. If the data is not normally distributed, the Mann-Whitney test is used.

\section{Ethical clearance}

This research has obtained the results of ethical eligibility through number 476/Panke.KKE/VI/2016 at Dr. Soetomo Teaching Hospital, Surabaya, Indonesia.

\section{Results}

This study involved 33 women with normal delivery and 34 cesarean sections. The number of primiparous women in February-May 2016 was 323 women. Score on normal delivery Edinburgh Postnatal DepressionScale(EPDS) $\geq 12 n=3$, EPDSscore $<12 n=30$ and cesarean delivery EPDS score $<12 n=30$ and EPDS score $\geq 12$. Table 1 shows that level of education, occupation, economic situation, communication with husband, Family planning, breastfeeding status, time to initiate postpartum sexual intercourse, and birth weight did not affect the choice of type of delivery for women.

Table 2 shows that the causes of perineal damage are mostly due to mediolateral episiotomy and the degree of perineal damage with Grade II status. An indication of elective cesarean section due to high myopia was found in 5 people (16.67\%). Perineal damage is mostly caused by mediolateral episiotomy (80\%).

Table 3 shows that there are no significant differences in the type of delivery, both normal delivery and cesarean delivery in desire, arousal, satisfaction, lubrication, orgasm, and dyspareunia, and the total female sexual index in primiparous.

\section{Discussion}

In this study, it is known that there is no difference in the results of the total score and the same 
Table 1: The relationship of several factors to the choice of delivery

\begin{tabular}{|c|c|c|c|}
\hline Variable & Normal, $\mathrm{n}=30(\%)$ & Sectio Caesarea, $n=30(\%)$ & $\mathrm{p}$-value \\
\hline Level of education & & & $0.237^{\mathrm{a}}$ \\
\hline Primary school & $3(10)$ & $3(10)$ & \\
\hline Junior high school & $6(20)$ & $4(13.3)$ & \\
\hline Senior high school & $16(53.3)$ & $13(43.3)$ & \\
\hline Bachelor degree & $5(16.7)$ & $10(33.4)$ & \\
\hline Work & & & $0.792^{\mathrm{b}}$ \\
\hline No & $19(63.3)$ & $17(56.7)$ & \\
\hline Yes & $11(36.7)$ & $13(43.3)$ & \\
\hline Economic Status & & & $0.980^{\mathrm{a}}$ \\
\hline Very less & 0 & $1(3.3)$ & \\
\hline Less & $2(6.7)$ & $1(3.3)$ & \\
\hline Enough & $26(86.7)$ & $26(86.7)$ & \\
\hline More than enough & $2(6.7)$ & $2(6.7)$ & \\
\hline Communication with husban & & & $1.00^{\mathrm{b}}$ \\
\hline Very communicative & $23(76.7)$ & $22(73.3)$ & \\
\hline Pretty communicative & $6(23.3)$ & $8(26.7)$ & \\
\hline Less communicative & 0 & 0 & \\
\hline Not communicative & 0 & 0 & \\
\hline Family planning & & & $0.792^{\mathrm{C}}$ \\
\hline Not & $9(60)$ & $6(40)$ & \\
\hline Hormonal combination & $5(62.5)$ & $3(37.3)$ & \\
\hline Single hormone & $14(70)$ & $6(30)$ & \\
\hline No hormonal & $2(11.8)$ & $15(88.2)$ & \\
\hline Breastfeeding status & & & $0.422^{b}$ \\
\hline Yes & $21(70)$ & $17(56.7)$ & \\
\hline No & $9(30)$ & $13(43.3)$ & \\
\hline Time to start sexual activity & $2.0(1.0-4.0)$ & $2.0(1.0-4.0)$ & $0.878^{\mathrm{a}}$ \\
\hline Month 1 & $1(3.3)$ & 0 & \\
\hline Month 2 & $17(56.7)$ & $18(60)$ & \\
\hline Month 3 & $11(36.7)$ & $11(36.7)$ & \\
\hline Month 4 & $1(3.3)$ & $1(3.3)$ & \\
\hline Birth Weight (gram) & $3026.66 \pm 367.82$ & $3011.66 \pm 386.11$ & $0.878^{\mathrm{C}}$ \\
\hline$<2500$ & $1(3.3)$ & 0 & \\
\hline 2500-3999 & $29(96.7)$ & $29(96.7)$ & \\
\hline$\geq 4000$ & 0 & $1(3.3)$ & \\
\hline
\end{tabular}

score in the FSFI in primiparous women after normal delivery or cesarean section. There were no significant differences in the two groups. Previous studies have investigated the type of labor and perineal trauma during labor. Sexual problems after childbirth and pain in primiparous women in the first 3 months after birth are about $80 \%$. Since cesarean delivery prevents damage to the perineum, it is thought that it may prevent sexual dysfunction from occurring after delivery. This is the main reason why some women and even obstetricians and gynecologists choose cesarean delivery in some countries even though there are no important data to support this opinion. In addition, several studies have shown that the mean scores for postnatal sexual function in women who have given birth by cesarean section are much better than for women who have had vaginal deliveries by episiotomy. Sometimes sexual changes after childbirth cause substantial disruption

Table 2: The causes of perineal damage

\begin{tabular}{ll}
\hline Variable & $\mathrm{n}(\%)$ \\
\hline Causes of perineal damage & \\
$\quad$ Mediolateral episiotomy & $24(80)$ \\
$\quad$ Spontaneous rupture & $6(20)$ \\
The degree of damage to the perineum & \\
Grade I & 0 \\
Grade II & $30(100)$ \\
Indications for elective cesarean section & $2(6.67)$ \\
Placenta previa totalis & $2(6.67)$ \\
Breech location + Oligohydramnios & $3(10)$ \\
Breech location + Postdate & $2(6.67)$ \\
Breech location & $3(10)$ \\
Latitude location & $3(10)$ \\
Cephalopelvic disproportion & $3(10)$ \\
Cephalopelvic disproportion + Postdate & $1(3.33)$ \\
Cephalopelvic disproportion + breech location & $5(16.67)$ \\
High myopia & $3(10)$ \\
Obesity grade III & $2(6.67)$ \\
Old primiparous & $1(3.33)$ \\
Big baby & \\
\hline
\end{tabular}

in the relationship between partners and only $15 \%$ of women suffering from sexual dysfunction consult a health care provider [7]. Women who delivered vaginally showed a significant reduction in desire, arousal, and lubrication domain scores 12 weeks after delivery compared to these scores on antenatal scare where other scores showed insignificant differences. Women who delivered with CS showed a significant difference in the desirability domain 12 weeks after delivery compared to this score on an antenatal care basis whereas other scores showed insignificant differences. It was concluded that the mode of delivery had no significant effect on female sexual function 12 weeks after delivery [10].

Table 3: Comparison of sexual function in primiparous women after normal delivery and cesarean section

\begin{tabular}{llll}
\hline Variable & Normal Delivery & Sectio Caesarea & p-value \\
\hline Desire & $3.54(1.2-6.0)^{\star}$ & $3.26(1.8-4.2)^{*}$ & $0.291^{\mathrm{a}}$ \\
Passion & $4.09 \pm 0.92$ & $3.93 \pm 0.86$ & $0.501^{\mathrm{b}}$ \\
Satisfaction & $4.70 \pm 1.16$ & $4.54 \pm 1.07$ & $0.582^{\mathrm{b}}$ \\
Lubrication & $4.36 \pm 0.92$ & $4.41 \pm 1.06$ & $0.847^{\mathrm{b}}$ \\
Orgasm & $4.60 \pm 0.86$ & $4.68 \pm 0.76$ & $0.706^{\mathrm{b}}$ \\
Dispareuni & $4.32 \pm 1.12$ & $4.70 \pm 0.83$ & $0.136^{\mathrm{b}}$ \\
Total FSFI & $25.62 \pm 4.18$ & $25.53 \pm 3.89$ & $0.934^{\mathrm{b}}$ \\
\hline FSFI. Fema
\end{tabular}

In this study, perineal damage was mostly caused by mediolateral episiotomy $(80 \%)$. High degree of perineal tear negatively affects female sexual function for up to 1 year after delivery. Evaluation of female sexual function and appropriate counseling is needed for women with perineal tearing, especially higher-grade tears [11]. Compared with women with an intact perineum, those who underwent episiotomy and second-degree perineal tear had high levels of libido, orgasm, and lower sexual satisfaction, and more pain during sexual intercourse. The presence of at least one sexual problem (reduced sexual arousal, reduced vaginal arousal, reduced vaginal lubrication, reduced orgasm frequency, dissatisfaction with sexual life, and dyspareunia) was statistically significantly more common after birth [12].

Female sexual dysfunction is very common and reportedly has a negative impact on quality of life. Significant risk factors for sexual dysfunction: sexual activity 2 weeks or less frequently, not a trigger for sexual activity with a partner, late restarting postnatal sexual activity (at 9 weeks or more), the first 5 months after delivery, primiparity, depression, and dissatisfaction relationship [13]. In addition, in this study, it was found that most of the research subjects gave breast milk. Breastfed babies were significantly less interested in sexual activity/having sex, and less sexual satisfaction than women who did not breastfeed. Almost all breastfeeding women suffer from sexual dysfunction. Regarding the components of sexual performance, the lowest scores are for libido and sexual arousal [14].

In a previous study, it was found that the most common postpartum sexual dysfunction is pain sexual dysfunction during sexual intercourse. There is a significant relationship between sexual dysfunction with factors such as length of marriage, number of 
children, family relationships, episiotomy status, and contraceptive methods [8]. Nearly two-thirds of women $(64.3 \%)$ reported that they had experienced sexual dysfunction during the $1^{\text {st }}$ year after delivery, and nearly three-quarters reported experiencing sexual dissatisfaction (70.5\%). The types of sexual dysfunction most commonly reported by affected women were sexual desire disorders (81.2\%), orgasm problems (53.5\%), and sexual arousal disorders (52.3\%) [13].

Sexual function, which is considered a part of women's health, is an important component of life and is a multi-dimensional phenomenon influenced by many biological and psychological factors. Sexual dysfunction refers to a chain of psychological experiences, individuals, and partners that manifest themselves as dysfunction in sexual desire, sexual arousal, orgasm, and pain during intercourse [15]. This needs to be a concern for health workers in preventing postpartum sexual dysfunction.

The next recommendation research is qualitative research to observe possible obstacles in interpersonal relationships with patients, there is a possibility that women's socio-cultural factors in Indonesia tend to influence respondents' answers to answering questionnaires in "safe" areas, namely, adequate answers and sex perceptions where there is still a taboo response. To express sexual problems to others.

\section{Conclusion}

The conclusion in this study is that there is no difference in the results of the total score and the same score in the FSFI in primiparous women after normal delivery or cesarean section. This study recommends that in primiparous care it is not advisable to choose one type of delivery as a form of prevention of postpartum sexual dysfunction. In addition, in the management of complaints of sexual dysfunction in primiparous, it is not required to consider the type of delivery as the main cause.

\section{References}

1. Soma-Pillay P, Nelson-Piercy C, Tolppanen H, Mebazaa A Physiological changes in pregnancy. Cardiovasc J Afr. 2016;27(2):89-94. https://doi.org/10.5830/CVJA-2016-021 PMid:27213856

2. Bhatia P, Chhabra S. Physiological and anatomical changes of pregnancy: Implications for anaesthesia. Indian J Anaesth. 2018;62(9):651-7. https://doi.org/10.4103/ija.IJA_458_18 PMid:30237589
3. Motosko CC, Bieber AK, Pomeranz MK, Stein JA, Martires KJ. Physiologic changes of pregnancy: A review of the literature. Int J Womens Dermatol. 2017;3(4):219-24. https://doi.org/10.1016/j. ijwd.2017.09.003

PMid:29234716

4. Hodgkinson EL, Smith DM, Wittkowski A. Women's experiences of their pregnancy and postpartum body image: A systematic review and meta-synthesis. BMC Pregnancy Childbirth. 2014;14:330. https://doi.org/10.1186/1471-2393-14-330

5. Henriques A, Alves E, Barros H, Azevedo A. Women's satisfaction with body image before pregnancy and body mass index 4 years after delivery in the mothers of generation XXI. PLoS One. 2013 Jul 31;8(7):e70230. https://doi.org/10.1371/ journal.pone.0070230

PMid:23936169

6. Widen E, Gallagher D. Body composition changes in pregnancy: Measurement, predictors and outcomes. Eur J Clin Nutr. 2014;68(6):643-52. https://doi.org/10.1038/ejcn.2014.40 PMid:24667754

7. Dabiri F, Yabandeh AP, Shahi A, Kamjoo A, Teshnizi SH. The effect of mode of delivery on postpartum sexual functioning in primiparous women. Oman Med J. 2014;29(4):276-279. https:// doi.org/10.5001/omj.2014.72

PMid:16871432

8. Banaei M, Moridi A, Dashti S. Sexual dysfunction and its associated factors after delivery: Longitudinal study in Iranian women. Mater Sociomed. 2018;30(3):198-203. https://doi. org/10.5455/msm.2018.30.198-203

PMid:30515059

9. Gutzeit O, Levy G, Lowenstein L. Postpartum Female Sexual Function: Risk Factors for Postpartum Sexual Dysfunction. Sex Med. 2020;8(1):8-13. https://doi.org/10.1016/j.esxm.2019.10.005 PMid:31837965

10. Eid M, Sayed A, Abdel-Rehim R, Mostafa T. Impact of the mode of delivery on female sexual function after childbirth. Int $\mathrm{J}$ Impot Res 2015;27:118-20. https://doi.org/10.1038/ijir.2015.2

PMid:25672800

11. Sayed Ahmed WA, Kishk EA, Farhan RI, Khamees RE. Female sexual function following different degrees of perineal tears. Int Urogynecol J. 2017;28(6):917-21. https://doi.org/10.1007/ s00192-016-3210-6.

PMid:27924373

12. Rathfisch G, Dikencik BK, Kizilkaya Beji N, Comert N, Tekirdag Al, Kadioglu A. Effects of perineal trauma on postpartum sexual function. J Adv Nurs. 2010;66(12):2640-9. https://doi.org/10.1111/j.1365-2648.2010.05428.x PMid:20735499

13. Khajehei M, Doherty M, Matt Tilley PJ, Saue K. Prevalence and risk factors of sexual dysfunction in postpartum Australian women. J Sex Med. 2015;12(6):12901. https://doi.org/10.1111/jsm.12901 PMid:25963126

14. Malakoti J, Zamanzadeh V, Maleki A, Farshbaf Khalili A. Sexual function in breastfeeding women in family health centers of Tabriz, Iran, 2012. J Caring Sci. 2013;2(2):141-6. https://doi. org/10.5681/jcs.2013.017 PMid:25276720

15. Banaei M, Azizi M, Moridi A, Dashti S, Yabandeh AP, Roozbeh N. Sexual dysfunction and related factors in pregnancy and postpartum: A systematic review and meta-analysis protocol. Syst Rev. 2019;8:161. https://doi.org/10.1186/ s13643-019-1079-4 